\title{
Study on the Impact of Cross-border E- commerce on the Development of Airport Economy in West China
}

\author{
Dan Wang \\ Xi'an Fanyi University, Xi'an, Shaanxi, 710105
}

\begin{abstract}
With the rapid spread of the Internet, e-commerce as a new way of trade, with unique advantages in the global context of vigorous development of international trade had a profound impact. E-commerce in China after 10 years of development, more and more foreign trade enterprises through e-commerce platform for international business activities, making e-commerce to promote the role of international trade gradually increased. In the context of economic globalization and information technology, seize the advantages of e-commerce to speed up Chinese trade transformation and upgrading is particularly important.

Keywords: Cross-border E-commerce, Airport Economy, West China
\end{abstract}

\section{Introduction}

As a fresh term, Cross-border E-commerce has only begun to appear in the field of business, government and academia in recent years, and has received a great deal of attention. The causes of the 2008 US financial crisis on the world's economic development has caused a major blow, which has a direct impact on Chinese export trade, export enterprises received foreign orders began to decline, especially small and medium-sized export manufacturing enterprises Hereinafter referred to the SME are the type of enterprise), suffered a "shortage of orders" situation. Coupled with Chinese appreciation of the renminbi, rising labor and raw material costs, increased difficulty of bank lending and trade policy changes and many other countries struck, making the survival of these enterprises have become even worse, unable to sustain and collapse, the remaining options Shut 
down or turn to domestic trade. Chinese urgent need for a new point of growth of foreign trade to change this situation, Cross-border E-commerce as a combination of international trade and e-commerce, began to be export enterprises and government attention, and rapid development. Cross-border E-commerce refers to the transaction subject of different customs, through the e-commerce platform to achieve the transaction, payment and settlement, and cross-border logistics service of goods, the completion of international business transactions. As a new trade model, Cross-border E-commerce has gradually played its potential in Chinese foreign trade. For Chinese small and medium enterprises, Cross-border E-commerce has greatly expanded their access to international markets, Development has brought a great opportunity.

\section{China Cross-border E-commerce Development}

Global Cross-border E-commerce statistics show that in 2014 the world's online retail e-commerce transactions reached 1.5 trillion US dollars, an increase of about $20.1 \%$. Asia-Pacific consumption will reach US \$ 525.2 billion and North America will reach US \$ 482.6 billion. Asia-Pacific's online shopping spending will surpass that of North America for the first time, making it the world's largest online retail market, while Europe and North America are still the world's largest. Important e-commerce market, respectively, accounted for $35.1 \%$ and $33.1 \%$ share of the world, Latin America is considered emerging markets for ecommerce, currently only $4.8 \%$, but with very large market potential. At present, compared with 10 trillion US dollars of global consumer goods trade market, ecommerce accounted for only a small part of the global e-commerce market annual growth of more than $20 \%$, Cross-border E-commerce market potential for the future, which Chinese development Cross-border E-commerce is very beneficial.

In recent years, Chinese Cross-border E-commerce development is rapid. Ministry of Commerce statistics show that in 2011, China Cross-border Ecommerce transaction volume of about 1.6 trillion yuan in 2012, about 2 trillion yuan in 2013 exceeded 3.1 trillion yuan in 2014 has increased to 40,000 Billion, to 2016 will increase to 6.5 trillion yuan, an average annual growth rate of close to $30 \%$, compared to the overall size of Chinese import and export trade market, the proportion is still low, only $9.6 \%$. According to eBay, the largest total crossborder retail export transactions in Greater China in the year of 2010 were Guangdong, Shanghai, Zhejiang, Beijing, Jiangsu, Fujian, Zhejiang and Jiangsu, with growth rates of $76.1 \%, 56.1 \%$ and $52.0 \%$ The fastest cross-border export center. Chinese enterprises to Cross-border E-commerce applications, from small businesses, medium-sized enterprises to large enterprises, and gradually increased, which in the performance of the most obvious network marketing, followed by ecommerce logistics links, electronic payment links are basically the same. At present, Chinese Cross-border E-commerce has developed rapidly, with great potential, with the introduction of relevant national policies will attract more and more small and medium enterprises to participate. 


\section{Present Situation of Airport Economic Zone}

The airport economy is a new type of regional economic system formed with the rapid development of air transportation. Based on the advantages of airport resources, the development of the industrial area in the vicinity of the airport is formed. The aviation network is becoming more and more perfect, the scale of aviation logistics is becoming stronger and stronger. The aviation logistics of our country keeps the same as that of Chinese aviation industry. With the continuous economic growth, With the development of the airport economy and the continuous expansion of the radiation range, the industrial structure of the airport economic zone will also change, generally divided into three stages: the transport economic stage, This stage is mainly dependent on air transport, related industries in the airport area and adjacent to the airport area, in order to facilitate at any time for air transport and airport operations to provide services; airport industry cluster stage, with the air passenger volume growth, airport concentration And the diffusion function gradually increased, thus attracting related industries in the airport economic zone near the concentration; urban economic stage, airport economy to the rapid growth, become the city's new growth pole, can attract high-tech enterprises to the resident, reduce the average land The impact of price on the city.Three levels of mutual promotion, with the continuous optimization of the structure of factors, can bring a powerful driving force for regional economic development.

\section{Analysis of Cross - border E-commerce and Inter-dynamic Development of Airport Economy}

Cross-border trade with e-commerce platform will be offline transactions "to pay" logistics and other sectors to achieve electronic integration of supply and demand both sides of resources, open up the upstream and downstream supply chain, including B2B, B2C platform model! Airport Logistics Park at this stage, Cross-border E-commerce platform and the combination of the airport economic zone, you can create a comprehensive set of import and export park! Crossborder E-commerce in the presence of customs clearance does not exist, Logistics cost is too high, logistics speed is slow, Cross-border E-commerce corporate brand building and other issues in the integrated park to be effectively resolved. Cross-border E-commerce development is the final stage of the formation of air transport, port services, distribution operations, bonded warehouse "online transactions" line display "payment of financial" courier delivery is one of the whole industry chain system. The upgrading of the industrial chain system can lead the airport economy to radiate the whole regional economy from the regional development, transform the airport economic zone into aviation city, further optimize the regional industrial chain and improve the regional environment, at present China has been combined with the Beijing-Tianjin-Hebei urban agglomeration. Planning and construction of the capital economic circle, play a 
new bridgehead role, and promote regional cooperation, build Beijing-TianjinHebei collaborative development demonstration area.

\section{Analysis of the Impact of E-commerce on Chinese International Trade in Airport Economy}

E-commerce has changed Chinese traditional way of foreign trade, there has been a "virtual market." In the traditional way of foreign trade, due to the constraints of information transmission, enterprises of goods from the factory to be experienced exporters, importers, distributors, wholesalers, retailers and other sectors can reach the hands of consumers, intermediate links, International market obstacles. E-commerce to break the constraints of information transmission, enterprises through EDI, Internet, electronic business platform, and other means to various types of commodity information in a centralized, open form released to the "virtual market."

Specific performance in: First, the trading tool. In the e-commerce mode, enterprises will trade the necessary product information, financial information, logistics information, etc. through the Internet to send, and through instant messaging tools, e-mail, video and other real-time online communication channels. The traditional way of payment of the airport economy includes delivery payment, document payment, account payment, collection payment and letter of credit payment. The payment process needs to fill in all kinds of bills and documents, and need to be designated by the banks . In e-commerce, the parties to the transaction to fill standardized, electronic format, a variety of bills and documents and transmitted through the network; shorten the time of document transmission; to be reached after the transaction, the final confirmation of payment on the network. Third, the delivery method. According to the physical form of different products, e-commerce delivery methods are also different. For example, the delivery of tangible products using international logistics delivery; intangible product delivery can be completed directly on the network.

The development of e-commerce has promoted the diversification of Chinese foreign trade. First, the impact of e-commerce trade intermediary organizations, to replace the role of traditional trade brokers, resulting in a "virtual" business. Individuals or organizations in their respective areas of expertise to master a core technology advantage, through the use of modern information technology industry will be a number of related enterprises or organizations linked into a network system in a more efficient manner to the international market to provide goods or services Of the "virtual" enterprises will emerge as the times require, mainly for the form of multinational strategic alliances.

Second, e-commerce reduces the threshold of SMEs to enter the international market. Since Chinese import and export right is difficult to obtain as well as the development of international markets need to spend a higher human, material and financial resources, Chinese foreign trade has long been the main body of largescale import and export right of export companies, industry and trade companies, 
foreign and joint ventures As well as other enterprises have the right to import and export monopoly, a large number of small and medium enterprises are excluded from the international market. With e-commerce in the airport economy in the wider application of more SMEs have the opportunity to e-commerce platform or self-built website to the international market customers about their products, services and corporate culture, establish a corporate image, direct Participate in international marketing activities, thereby expanding the scope of the marketing market, and promote Chinese small and medium enterprises to the international road. As of March 31, 2012, Alibaba Chinese and international website registered users amounted to 79.8 million, a total of 10.3 million corporate shops. A large number of small and medium-sized enterprises in China use Alibaba international station trade platform to show to the international market customers, promote their own products and services, and then access to trade opportunities and orders.

E-commerce can promote the airport economic regulatory innovation. The traditional airport economic supervision system mainly includes customs supervision, customs policy and import and export inspection and quarantine. With the wide application of e-commerce in the airport economy, the networkbased and invisible supervision of the airport economy in the process of ecommerce transaction Put forward higher requirements. In recent years, our government has been actively strengthening the supervision of e-commerce applications in the airport economy.

\section{Conclusion}

Compared with the traditional e-commerce, Cross-border E-commerce from the online purchase to offline transactions, have encountered new difficulties and risks, this paper combines the new features of Cross-border E-commerce in China, Economic zone to establish business or logistics transport warehousing business, an effective solution to China Cross-border E-commerce operation of the problems.

\section{Acknowledgement}

Business Sector of Trade Promotion Committee, 13th Five-Year Plan Project "Cross-border electronic commerce and inland airport economy coordinated development" (XXHKTB-1637)

\section{References}

[1] Wang Zuqiang, Zheng Chunfeng. Facilitating the development of crossborder E-commerce ideas and countermeasures [J] .E-commerce, 6(1), pp. 8-14, 2015 
[2] Tang Yinghan. Chinese e-commerce development level and spatial differentiation [J]. Economic Geography, 5(5), pp. 21-31, 2015

[3] Shi Quan, Zhong Hua. Study on the Framework of E-Commerce Import Control System for Cross-border Trade [J]. Journal of Customs and Trade Studies , 2(5), pp. 12-19, 2015

[4] Fan Wenjing. Cross-border E-commerce development and transformation of Chinese foreign trade model [J]. Foreign Economic Relations and Trade, 4(3), pp. $103-105,2015$

[5] Huang Yanling. Application of enterprise e-commerce measurement index system [J]. Inner Mongolia Science Technology and Economy, 20(3), pp. 78-82, 2014 